\title{
Improving Literacy Skills: A Call to Action
}

\section{Canadian Education Association}

Permission to reprint this excerpt was provided by Gina Lorinda Yagos, Knowledge Officer, of the Canadian Education Association. To access the complete text of this important document visit http: // www.cea-ace.ca

A Canadian Agenda for Literacy must take a life course perspective, addressing factors from before birth to old age that positively impact literacy development and that are amenable to public policy action. The agenda should include policies aimed at

(a) improving literacy skills and

(b) ensuring that literacy skills are required and valued in both social and economic contexts.

The following policy objectives are based on policies, practices and strategies that have been shown to improve literacy in a variety of contexts. Because literacy learning and literacy activities permeate many areas of personal and public life, and because Canada's political and social institutions cross several jurisdictional boundaries, it is not always possible to clearly identify who should be responsible for developing and implementing specific policies designed to improve literacy. The overarching requirement, therefore, is for a national strategy that calls on all levels of government to work with all partners to meet the literacy needs of Canada.

\section{a) Improving literacy skills}

Policies to improve the literacy success of young children should include:
- Improving pre-natal maternal health and well-being, ensuring that pregnant women are less vulnerable because of poor nutrition, smoking, and substance abuse, since these factors have a significant impact on the educability of their children.

- Screening for developmental problems following birth to reduce the number of children who will later encounter difficult learning problems that will impair their literacy.

- Increasing the opportunity and readiness to learn across social groups by providing subsidized high quality childcare and other pre school environments especially for children from disadvantaged back-grounds.

- Encouraging parents to read to their children and provide access to quality reading material.

- Raising the level of financial support to poor families with children.

Policies to improve the literacy success of school-age children and youth should include:

- Simultaneously pursuing the goals of excellence and equity in learning outcomes for all children including:

$\checkmark$ identification and support for children who are struggling to read;

$\checkmark$ access to diagnostic and remedial services;

$\checkmark$ smaller class sizes in primary grades;

$\checkmark$ a strong and demanding curriculum;

$\checkmark$ a thoughtful assessment system;

$\checkmark$ access to a wide range of learning resources; $\checkmark$ a classroom climate that is conducive to learning;

$\checkmark$ engaging parents in support of their children's learning;

$\checkmark$ raising teacher expectations in respect of the capacity of children and youth to become literate.

- Ensuring that teachers, particularly primary teachers, receive specialized preparation in reading instruction.

- Increasing access to and participation in post-secondary reading materials in official languages in minority education, including reducing the cost of attendance through reasonable tuition costs, tax credits and provide better access to needs-based financial assistance for post secondary education.

- Providing opportunities for students whose first language - is neither English nor French to acquire full literacy in at least one official language.

Policies to improve the literacy of adults should include

- Increased direct funding for adult literacy and basic adult education programs.

- Improved curricula, instructional and assessment methods for adult literacy.

Funding for appropriate bodies to investigate the human resource development needs, including literacy requirements of specific industrial sectors.

- Support for family literacy programs that seek to simultaneously improve the literacy levels of multiple generations.

- Guaranteed access to language learning programs in at least one official language for adult speakers of languages other than English and French

b) Ensuring that literacy skills are required and valued in both social and economic contexts. 
Policies to meet these objectives should include:

- Development of tools to assess prior learning and experience, particularly those of immigrants, in order to establish equivalent credentials.

- Cooperative efforts to increase the portability of credentials in order to improve mobility of both students and workers and to increase the effectiveness of pre-employment and promotion screening.

- Community access to the World Wide Web and digital resources in all Canadian communities.

- Increased support for libraries and electronic access to reading materials in official languages in minority contexts and for non -official language speakers.

- Tax policies to reduce the cost of reading materials.

- Incentives for firms to offer more training, including literacy training.
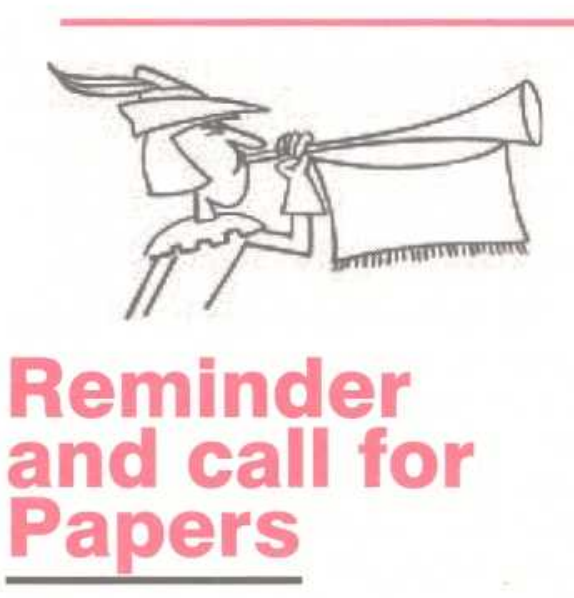

In $\mathrm{n}$ an attempt to bring the issues and the academic year in sync the next issue of Teaching and Learning will be will be published in October. Please note we are still accepting articles, resources, exemplary lessons, book reviews etc. for the theme "Teaching Character, Life and Resilience Skills in Schools; however, we also want to include articles and resources that deal with
- Social marketing to increase the reading behaviour of adults and increase appreciation for the value of literacy.

- Support for research into and dissemination of information on literacy - its level, distribution, determinants and outcomes.

\section{The Call to Action}

We know what policies, practices, and educational strategies will improve literacy levels. What we need is the political and professional determination to act on this knowledge.

Canada is a nation rich in human and economic resources, poised to be a major contributor to the growing global knowledge-based economy. Its governments and its people profess a commitment to education, and its institutions are built around the assumption of a literate public. And yet, almost half of adult Canadians function at a literacy level inadequate to meet the demands

Health, Wellness and Safety in schools.

Manuscripts must be submitted electronically. Please use a recent edition of Microsoft Word. Proof read articles and other submissions must not exceed 3000 words including a short bio of no more than 60 words. Shorter articles are welcomed. If a submission is accepted authors are asked to submit a recent photograph (head shot only). All submissions are subject to review and editing.

\section{Subscriptions}

In order to help defray the cost of producing this journal we are embarking on a campaign to increase individual subscriptions and include select advertising. Our subscription rates are very reasonable. Consider joining our subscription list. We invite you to of their daily lives, and too many young people still leave school poorly equipped to pursue post-secondary education or meaningful work.

Clearly, if we are to maintain our place in the new economy, and if our people are to enjoy the full benefits of Canadian society, leaders at all three levels of government, in school districts and educational institutions, in the private sector and NGOs, in civil society and communities throughout the country, will need to demonstrate a collective commitment to collaborative action. We call upon all governments to work together to provide a strategic framework and the actions required for all Canadians to achieve the levels of literacy they desire and our country needs.

The complete text and references for this documents is available at

Canadian Education Association http://www.cea-ace.ca consider purchasing subscriptions for a teacher, friends, a school, a library, a parent's council, a resource room. Principals might consider multiple copies for staff. Instructors are invited to consider current and back issues for professional development courses. Rates for multiple copies involve significant discounts.

Please forward all requests to:

Raymond Chodzinski, Ph.D

Editor

Teaching and Learning c/o Nancy Scheoberle

Faculty of Education

Brock University

1842 King Street East

Hamilton, Ontario

L8K 1 V7

Nancy@foed.brocku.ca 